\title{
Physiotherapy in Bangladesh: Inequality Begets Inequality
}

\section{Firoz Ahmed Mamin* and Rieke Hayes}

Department of Physiotherapy, Bangladesh Health Professions Institute, Centre for Rehabilitation of the Paralysed, Savar, Dhaka, Bangladesh

Background: The demand for health services in developing countries often outweighs provision. This article describes the present condition of physiotherapy in Bangladesh. Physiotherapy is not recognized as a profession by the government. There is no single registration and regulation body. The health-related and economic benefits of physiotherapy are not felt by the majority of Bangladeshi citizens.

Areas covered: The burden of disease is changing, and Bangladesh needs a profession that specializes in physical rehabilitation to face these challenges. This article outlines the benefits to patients and the wider economy from a broad physiotherapy regime for all Bangladeshi citizens. It describes the many barriers the profession faces.

OPEN ACCESS

Edited by:

Edward Broughton,

University Research Co.,

United States

Reviewed by:

Melanie Natascha Tomintz,

University of Canterbury,

New Zealand

Marisa Theresa Gilles,

Western Australian Center for

Rural Health (WACRH), Australia

*Correspondence:

Firoz Ahmed Mamin

mamincns@gmail.com

Specialty section:

This article was submitted to Public Health Policy, a section of the journal

Frontiers in Public Health

Received: 22 November 2017

Accepted: 05 March 2018

Published: 23 March 2018

Citation:

Mamin FA and Hayes R (2018)

Physiotherapy in Bangladesh:

Inequality Begets Inequality.

Front. Public Health 6:80.

doi: 10.3389/fpubh.2018.00080
Conclusion: Physiotherapy is efficacious in many post-trauma situations and long-term conditions. Economic evidence supports the provision physiotherapy as a cost-effective treatment which should be considered as part of the provision of a universal health-care service. Official recognition of the protected "physiotherapist" title and a single registration and regulation agency are recommended.

Keywords: Bangladesh, sustainable development goals, universal health coverage, rehabilitation, physiotherapy

\section{INTRODUCTION}

Physiotherapists are specialists in developing and maintaining people's ability to move and function throughout all stages of their lives. They promote healthy lifestyles, treat, and prevent many problems caused by illness, injury, pain, disease, age, and inactivity. They work with people affected by a range of conditions including arthritis, back pain, lung disease, spinal cord injuries, falls, stroke, incontinence, fractures, burns, and mental health issues. The ultimate goal of rehabilitation is to provide the individual with the best possible opportunity for full and effective participation and inclusion in society. Physiotherapists work in many diverse settings, including hospitals, emergency medical teams, community settings, hospices, nursing homes, health centers, education, and research.

In many developing countries, physiotherapy is poorly understood and therefore lacks the recognition, funding, and resources to be utilized effectively. Bangladesh is no exception to this.

Bangladesh became an independent state in 1971. The National Institute of Traumatology and Orthopedic Rehabilitation (NITOR) was established to treat and rehabilitate those wounded during

Abbreviations: BHPI, Bangladesh Health Professions Institute; NCD, noncommunicable disease; NGO, nongovernmental organization; NITOR, National Institute of Traumatology and Orthopedic Rehabilitation; RTA, road traffic accident; SDG, sustainable development goals; USD, United States Dollar; WHO, World Health Organization. 
the war of liberation with Pakistan. This demand for rehabilitation specialists led to the development of the first physiotherapy course in the country in 1973. This course only saw two classes graduate before it was discontinued (1).

Through involvement with Dhaka University, the Bangladesh Health Professions Institute (BHPI) and NITOR developed a BSc degree in physiotherapy in the 1990s. This course was a 4-year program with over 1,000 clinical placement hours, followed by a 1 -year compulsory internship, a model which is still in use today.

To date, there are seven institutions which provide a BSc Physiotherapy qualification: BHPI, NITOR, Dhaka Institute of Health and Technology, Rajshahi Institute of Health and Technology, State College Health Sciences, SAIC Institute of Medical Technology, and Gono Bishwabidyalay. In addition to this, both the BHPI and Gono Bishwabidyalay provide an MSc Physiotherapy program.

There is a severe shortage of physiotherapists to serve the huge population of Bangladesh. Whereas approximately 54.7 thousand physiotherapists were registered in the United Kingdom in 2017 (2) (a population of around 65 million), only an estimated 1.7 thousand physiotherapists exist in Bangladesh today (a population of around 160 million). This estimate is based on the number of graduates reported since the 1990s. Ironically, the employment opportunities for these physiotherapists are very limited. Many graduates set up private practices and few find work in private hospitals, nongovernmental organizations (NGOs), or seek employment abroad. As the profession has no formal register, no exact figures currently exist on how many of these graduates are currently practicing as physiotherapists.

This bleak situation can be largely attributed to one major issue: BSc physiotherapists are not formally recognized by the government. As a result, they are not employed to work clinically in the public health sector. Despite BSc qualifications being issued by government institutions, only diploma physiotherapists (known as health or medical technologists) are employed to work in public hospitals at this time (3). This work is carried out under the instruction of a physiatrist (a doctor trained in physical medicine), rather than a physiotherapist, and is largely restricted to electrotherapy in a musculoskeletal outpatient setting.

Physiotherapy lacks an official definition as a discipline among other health services in both the Bangladesh National Health Policy 2011 and the Health, Population and Nutrition Sector Development Program 2011-2016. Acute physical rehabilitation has almost been absent under the Ministry of Health and Family Welfare while long-term rehabilitation has been provided under the Ministry of Social Welfare and NGOs (3). There is a lack of coordination between these health and social welfare agencies (4).

Bowing to the growing pressure from student groups, which culminated in a hunger strike in 2010, the government allocated land and funding to create the Bangladesh College of Physiotherapy in Dhaka in $2011(5,6)$. The building never began construction, however, and the land plot is currently being used as an urban slum (7). The National Health Policy 2011 made a single reference to physiotherapy, stating that the profession required further development. It contained no plan as to how it should be developed nor was follow-up action taken after the publishing of this policy. On the other hand, the policy called for further investment in alternative therapies such as unani, ayurvedic, and homeopathy training and recruitment. These professions are formally recognized by the government, registered, trained in state colleges, and are employed in public hospitals (8). Tackling the perception that physiotherapy and physical rehabilitation are not essential to health care is a pivotal step to addressing this poor investment from the government.

\section{TITLE AND REGISTRATION ISSUES}

By denying the profession recognition at a government level, the state has also rendered it free from governance. The title of physiotherapist is neither protected nor regulated. This is understandably a concern, as a regulatory body is in place to protect the public as much as they protect the profession itself.

Professional bodies do exist, but their role is limited to advocacy, peer support, and professional development. At present, two such groups exist: the Bangladesh Physiotherapy Association, which is a member of the World Confederation of Physical Therapists, and also the Bangladesh Physical Therapy Association $(1,9)$. Membership with either, though encouraged, is not obligatory. They represent, but they do not regulate the profession in Bangladesh.

The lack of registration also means that little information exists about the availability, accessibility, and quality of the physiotherapy service. Through a register of accredited professionals that meet a set of standards in education, skill, conduct, and behavior, it would be an offense, punishable by law, to use a protected title inappropriately; thus potentially dangerous practice could be prevented. A regulatory body aims to uphold high standards of education and training in order to ensure good practice within the profession. Such safeguards exist to ensure the professionalism and accountability of the physiotherapy profession, thus protecting the public from malpractice.

Professional registration and regulation is a crucial step to legitimizing and empowering the physiotherapy profession in Bangladesh.

\section{THE BANGLADESHI HEALTH CARE}

Though exact figures for the population vary, the consensus is that the population currently sits at around 160 million people, making it one of the most densely populated countries in the world at 1,252 people per $\mathrm{km}^{2}$ (10).

An estimated $70 \%$ of the population live in rural areas. However, Bangladesh is going through rapid urbanization generating cities of unprecedented density and congestion (11). Dhaka, its capital, is considered the most densely populated city in the world with 44,500 people per $\mathrm{km}^{2}$ (12).

Though considered a developing, lower middle-income country, progress has been made toward eradicating poverty over the past 30 years, reducing poverty from $57 \%$ in $1991-1992$ to $25 \%$ in 2015 (13). Vision 2021 sets the poverty target at 14\% which, if achieved, would result in Bangladesh becoming a middle-income country by 2021 (14). 
Bangladesh has the lowest spending on health per capita in South Asia. In the 2015-2016 fiscal year, only $4.3 \%$ of the national budget was allocated to the health sector equating to 32 United States Dollar (USD) per capita. This is considerably below the World Health Organization (WHO) recommended level of $15 \%$, which is a per capita spending of 54 USD (15). Despite this, Bangladesh has achieved remarkable accomplishments in many areas of health in the face of its economic poverty.

Maternal mortality decreased by 75\% since 1980 (16). Infant mortality more than halved since the 1990s (11). Life expectancy now averages 72 years, and it is estimated that almost $19 \%$ of the population will be over 60 years of age by mid-century (17).

Many of these improvements have been attributed to the use of pluralism (18). Following the formation of state, the government encouraged an environment in health care, and social welfare could be supplemented considerably by outside donors, NGOs, and private enterprises.

The government provides hospitals at district and subdistrict (Upazila) levels in Bangladesh. Although the public health system is, in principle, free to the population, it does incur costs indirectly through medication, laboratory tests, surgical instruments, and transport costs. Staffing for public health services is limited. There are 4.9 doctors and 2.9 nurses registered for every 10,000 residents in Bangladesh; however, only 1.43 and 1.05, respectively, per 10,000 population work in public health care (19). The health worker density needed to address the sustainable development goals (SDGs) is estimated at 4.45 doctors, nurses, and midwives per 1,000 population (20). The issues within the public health sector are considerable: critical staff are absent, facilities are inadequate, quality of staffing is poor, patients often travel great distances to facilities, there are informal fees, poor or absent communication, and long waiting times. Poor governance and accountability within the health sector exacerbate these problems (21). These issues and the perception of poor and unreliable services may explain why those who can afford it often seek private health-care services (22).

In addition to severe shortages, Bangladesh's health workforce is also characterized by its inequitable and uneven geographical distribution. The already-limited medical and nursing staff, whether private or public, are concentrated predominantly in urban areas. The vacancy rate for all medical staff is low in Dhaka but often rises significantly with an increasing distance from the capital. On average, the vacancy rate was $43.3 \%$ for physicians in 2011 with the highest vacancy reported in Gaibandha district at $80.5 \%$ (21). This leaves over $70 \%$ of Bangladesh's population, who live in rural areas, with very minimal access to free public health care. These people are also among the poorest in the country. Frontline health services in rural settings thus tend to be informal "village doctors" and unregistered drug vendors. The proliferation of unregulated, often low-quality, and high cost private practitioners is fast becoming a concern for public safety (23).

The private sector dominates health care. In 2011, $80 \%$ of hospitals were private for profit, accounting for $50 \%$ of all hospital beds in Bangladesh, and this figure continues to grow every year (24). Around $50 \%$ of doctors and $42 \%$ of nurses in Bangladesh work exclusively for the private sector, with many additional staff working in both private and government hospitals (25). This duality has been known to affect public sector services where informal payments by patients for free or unnecessary services add up to $80 \%$ of what is spent more formally on fees in private sector facilities (18). Almost two-thirds of health-care costs in a household expenditure are in the private sectors (18). Even in urban areas, however, where the availability of health care is significantly greater, hospitals and services are often financially and socially unattainable to the population (26). Accessing the nearest clinic, which is usually private, can be achieved a few times in life because the majority of Bangladeshis simply cannot afford to. However, these are the people who need it the most, for poor health and disability can cause poverty and poverty can exacerbate disability. For a poor population with growing longterm conditions, there is a need for accessible and affordable public health care (11).

It is estimated that 4,000 NGOs, both national and international organizations, provide health-care services in areas which remain underfunded and understaffed by the state (27). These areas include, but are not limited to, women's health, rehabilitation, orthotics and prosthetics, education, and care for people with disabilities.

\section{PROVISION OF REHABILITATION SERVICES}

Rehabilitation services in public and private health care do not exist in Bangladesh, and this paucity is being only addressed, by some degree, by NGOs. As a result, physiotherapy is not sufficiently included in health policies by the government and is both under-resourced and underfunded. The government recruits no qualified physiotherapists in the public health sector. Stroke, fractures, amputees, and spinal cord injuries are just a few of the many conditions that receive neither inpatient nor community rehabilitation through the public sector. Many of these patients are simply discharged home once medically fit without any follow-up or rehabilitation which could reduce their dependence and help integrate them into society. This is a significant oversight by a government that is committed to implementing the global 2030 SDGs. Universal health coverage is a prominent part of the SDGs and aspires to ensure that all people can use the promotive, preventative, curative, rehabilitative, and palliative health services they need, while also ensuring that the use of these services does not expose the user to financial hardship (28). The staffing crisis compounds the public health service inefficiencies. In order to reach its goal by 2030 , the country will have to improve the availability and the skill mix of its health workforce (29), and acknowledging the specialty of physiotherapist in providing rehabilitation is an essential step.

The burden of disease in Bangladesh is shifting. The population is growing in size, and there is also a shift in not just an aging but an old population (17). Increased urbanization, matched by a rapidly developing infrastructure, is increasing the number of vehicles on the road and is shifting work sector toward the garments industry. The prevailing health and disease profiles are 
changing in Bangladesh, and the health sector needs to change with it.

According to the WHO, 15\% of the world's population suffers some form of disability and $80 \%$ of these can be found in developing countries $(30,31)$. Gupta et al. estimates that $92 \%$ of the disease burden in the world is related to causes requiring health professionals associated with physical rehabilitation (32).

Noncommunicable diseases (NCDs), including injuries, now account for $60 \%$ of deaths in Bangladesh (33). A 2010 government survey found a high incidence of smoking (26\%), diabetes (3.9\%), hypertension (17.9\% stage I, 5.5\% stage II), and low physical activity (27\%) within Bangladesh (34). These are all contributing factors to NCDs such as cancer, chronic lung diseases, stroke, and other cardiovascular disease, which fall under the top five causes of death in the country (33). The size and skill of the current health workforce is inadequate to deal with an increasing prevalence of NCDs which require a huge preventative health care. Rehabilitation specialists such as physiotherapists remain a largely untapped resource in Bangladesh. Participation in physical exercise can help prevent and reduce many chronic diseases, and physiotherapists can advise on the management and prevention of future health problems associated with NCDs. According to the WHO estimate 2011, the cost of preventative action would be US $\$ 11.4$ billion per year across all low- and middle-income countries which equates to the annual cost of less than US\$1 per person living in a low-income country (35). Addressing NCDs should be the top priorities not only for health but for rapid economic development of the country through saving scarce resources.

Manual labor and the garments industry are noted for their poor work conditions. In a small-scale study, almost $62 \%$ of workers in a garments factory suffered some form of musculoskeletal problems (36). According to the Global Burden of Disease 2015 study, the health problems, which resulted in the two highest causes for disability in Bangladesh, were back and neck pain and "other musculoskeletal problems" (37). Physiotherapy is effective in reducing both acute and chronic pain, limiting the risk of further disability and contributes to improved physical function, including return to work and recreational activity (38-40).

Rising motorization in South Asia has not been accompanied sufficiently by improvements in road safety strategies. According to a WHO report, 1.3 million deaths globally are due to road traffic accidents (RTAs), $90 \%$ of which occur in low- to middleincome countries (41). In addition to this, between 20 and 50 million people are estimated to have nonfatal injuries, with many of those who survive left with temporary or permanent disabilities. According to the Bangladesh Health and Injury Survey 2016, there are over 23,000 road traffic fatalities a year in Bangladesh, equating to 64 deaths a day. Over 3.4 million people a year suffer nonfatal injuries as a result of RTAs with over 80,000 experiencing permanent disability (42). One of the recommendations of the study is to strengthen rehabilitation interventions for these victims.
In addition to the physical and emotional toll on those affected, disabilities can also incur a considerable economic loss to victims, their families, and the nation as a whole. Losses arise from the cost of treatment, reduced or lost wages, and for family members who need to take time off work to care for the disabled. A study published in April 2017 found that residents in Bangladesh faced serious difficulties with health-care financing; 1 in 10 households incurred financial catastrophe and 1 in 20 non-poor households became poor due to health-care costs (43). Those who are poor are more likely to become disabled, and those who are disabled are more likely to become poor.

Besides the direct benefits physiotherapy can have to the health and quality of life of a patient population, rehabilitation can also have a positive impact on the economy. A period of structured rehabilitation for injuries and musculoskeletal problems can reduce the degree of impairment, restoring function, improving recovery time, and return to work, thus reducing the financial burden $(44,45)$. At present, the health system does not have the capacity to answer the needs of these patients, leaving them without a proper treatment, at risk of further complications and hamper their reintegration into society. Physiotherapy plays an integral role to promoting and improving health in a population.

With this in mind, it is vital that the government addresses the paucity in a workforce that is skilled in addressing rehabilitation needs, thus improving quality of life and enabling those with disabilities to be able to contribute to the economy. The sustainable development agenda cannot be effectively achieved without addressing the unmet needs for rehabilitation services (46).

\section{CONCLUSION}

Bangladesh is moving toward universal health coverage. Health workforce planning must address how to meet the twin goals of increased accessibility and provision of high-quality care. Three elements must now be considered. First, the recognition of the protected title of physiotherapist along international standards, in tandem, a merged, single registration and regulation agency. Second, a commitment to the provision of physiotherapist posts in proportion to the expansion of a universal health-care mandate. Third, an evaluation in the Bangladeshi context of the explicit link between physiotherapy provision and the improved quality of life, integration into society, return to employment, and reduction of financial burden associated with illness.

\section{AUTHOR CONTRIBUTIONS}

All authors contributed equally in the research and write-up to this article.

\section{ACKNOWLEDGMENTS}

We would like to acknowledge the contribution of Stephen Kinsella in improving the readability of this article. 


\section{REFERENCES}

1. Bangladesh Physiotherapy Association. (2017). Available from: http://www. bpa-bd.org (accessed June 28, 2017).

2. Health and Care Professions Council. Physiotherapists-Number of Registrants. (2017). Available from: http://www.hcpc-uk.org/aboutregistration/professions/index.asp?id=11 (accessed October 03, 2017).

3. Ahmed SM, Alam BB, Anwar I, Begum T, Huque R, Khan JAM, et al. Bangladesh Health System Review. (Vol. 5). Health Systems in Transition (2015). 3 p.

4. Axelsson C. Mapping Report of Physical Rehabilitation Services. Afghanistan, Bangladesh, Odisha (India), Sri Lanka: Handicap International (2014).

5. Fast-Unto-Death: Physiotherapy Students Fall Sick. The Daily Star (2010). Available from: http://www.thedailystar.net/news-detail-144094 (accessed September 25, 2017).

6. Government of the People's Republic of Bangladesh, Ministry of Health and Family Welfare - Planning Wing. Strategic Plan for Health, Population \& Nutrition Sector Development Program 2011 - 2016. Program Implementation Plan-Volume 1. (2011). Available from: http://www.nationalplanningcycles. org/sites/default/files/country_docs/Bangladesh/bangladesh_hpnsdp_ 2011-2016.pdf (accessed August 10, 2017).

7. Haque MM. Urgency of Government Physiotherapy College in Bangladesh. J Neurol Stroke (2017) 6(6):00221. doi:10.15406/jnsk.2017.06.00221

8. Government of the People's Republic of Bangladesh, Ministry of Health and Family Welfare. National Health Policy 2011.(2017). Availablefrom: http://www. mohfw.gov.bd/index.php?option=com_docman\&task=doc_download \& gid=1475\&lang=en (accessed September 26, 2017).

9. Bangladesh Physical Therapy Association. (2017). Available from: http://www. bd-bpa.org/ (accessed August 16, 2017).

10. World Bank. Bangladesh Country Profile. (2017). Available from: http://data. worldbank.org/country/bangladesh (accessed September 25, 2017).

11. Chowdhury MR, Bhuiya A, Chowdhury ME, Rasheed S, Hussain Z, Chen LC. The Bangladesh paradox: exceptional health achievement despite economic poverty. Lancet (2013) 382:1734-45. doi:10.1016/S0140-6736(13)62148-0

12. UN Habitat. Dhaka. (2017). Available from: http://urbandata.unhabitat. org/data-city/?cities=6081\&indicators=urban_agglomeration_population_ density (accessed September 27, 2017).

13. General Economics Division Planning Commission - Government of the People's Republic of Bangladesh. Millennium Development Goals: Bangladesh Progress Report (2015) Chapter 2: Goal 1: Eradicate Extreme Poverty and Hunger. (2017). Available from: http://www.plancomm.gov.bd/wp-content/ uploads/2015/09/MDGs-Bangladeh-Progress-Report_-PDF_Final_ September-2015.pdf (accessed July 09, 2017).

14. General Economics Division Planning Commission - Government of the People's Republic of Bangladesh. Perspective Plan of Bangladesh 2010-2021 Making Visions 2021 a Reality. (2012). Available from: http://www.plancomm. gov.bd/perspective-plan/ (accessed July 10, 2017).

15. Hassan MZ, Fahim SM, Zafr AHA, Islam MS, Alam S. Healthcare financing in Bangladesh: challenges and recommendations. Bangladesh J Med Sci (2016) 15:505-10. doi:10.3329/bjms.v15i4.21698

16. Hogan MC, Foreman KJ, Naghavi M, Ahn SA, Wang M, Makela SM, et al. Maternal mortality for 181 countries, 1980-2008: a systematic analysis of progress towards Millennium Development Goal 5. Lancet (2010) 375: 1609-23. doi:10.1016/S0140-6736(10)60518-1

17. El-Saharty S, Ahsan KZ, Koehlmoos TL, Engelgau MM. Tackling Noncommunicable Diseases in Bangladesh: Now Is the Time. Washington, DC: World Bank Group (2013). Available from: http://documents.worldbank.org/ curated/en/161821468209952095/Tackling-noncommunicable-diseases-inBangladesh-now-is-the-time (accessed September 26, 2017).

18. Ahmed SM, Evans TG, Standing H, Mahmud S. Bangladesh: innovation for universal health coverage 2. Harnessing pluralism for better health in Bangladesh. Lancet (2013) 382:1746-55. doi:10.1016/S0140-6736(13)62147-9

19. Government of the People's Republic of Bangladesh, Ministry of Health and Family Welfare. Chapter 1: Health Bulletin 2016. (2017). Available from: http:// www.dghs.gov.bd/images/docs/Publicaations/HB\%202016\%20_2nd_edition_13_01_17.pdf (accessed July 10, 2017).

20. Scheffler RM, Cometto G, Tulenko K, Bruckner T, Liu J, Keuffel EL, et al. Health Workforce Requirements for Universal Health Coverage and the Sustainable Development Goals_Background Paper N.1 to the WHO Global
Strategy on Human Resources for Health: Workforce 2030. Human Resources for Health Observer Series No 17. Geneva: World Health Organization (2016).

21. Rose J, Lane TM, Rahman T. Bangladesh Governance in the Health Sector: A Systematic Literature Review. Washington, DC: World Bank Group (2014). Available from: http://documents.worldbank.org/curated/en/366061468004785129/ Bangladesh-governance-in-the-health-sector-a-systematic-literature-review (accessed September 10, 2017).

22. Andaleeb SS, Siddiqui N, Khandakar S. Patient satisfaction with health services in Bangladesh. Health Policy Plan (2007) 22(4):263-73. doi:10.1093/ heapol/czm017

23. Das P, Horton R. Bangladesh: innovating for health. Lancet (2013) 382(9906):1681-2. doi:10.1016/S0140-6736(13)62294-1

24. Huque R, Barkat A, Nazme S. Chapter 3: public health expenditure: equity, efficacy and universal health coverage. In: Ahmed SW, Evans TG, Chowdhury AMR, Mahmud S, Bhuiya A, editors. Bangladesh Health Watch. Moving Towards Universal Health Coverage. Dhaka: James P Grant School of Public Health, BRAC University (2012). p. 25-32.

25. Ministry of the People's Republic of Bangladesh, Ministry of Health and Family Welfare. Health Bulletin. (2013). Available from: www.dghs.gov.bd/ images/docs/Other_Publication/HB\%202013\%20final\%20-\%20Full\%20 version\%201March14.pdf

26. Ahmed SM, Hossain MA, RajaChowdhury AM, Bhuiya AU. The health workforce crisis in Bangladesh: shortage, inappropriate skill-mix and inequitable distribution. Hum Resour Health (2011) 9:3. doi:10.1186/14784491-9-3

27. National Institute of Population Research and Training (NIPORT), Ministry of Health and Family Welfare. Bangladesh Health Facility Survey 2014. Dhaka, Bangladesh (2016). 6 p. Available from: http://www.aidsdatahub.org/ sites/default/files/publication/Bangladesh_health_facility_survey_2014.pdf (accessed August 20, 2017).

28. United Nations General Assembly. Transforming Our World: The 2030 Agenda for Sustainable Development. A/RES/70/1. (2015). Available from: http://www.un.org/ga/search/view_doc.asp?symbol=A/RES/70/1\&Lang=E (accessed October 04, 2017).

29. El-Saharty S, Sparkes SP, Barroy H, Ahsan KZ, Ahmed SM. The Path to Universal Health Coverage in Bangladesh: Bridging the Gap of Human Resources for Health. A World Bank Study. Washington, DC: World Bank Group (2015).

30. World Health Organization. World Report on Disability: Summary. (2011). Available from: http://www.who.int/disabilities/world_report/2011/report. pdf (accessed July 26, 2017).

31. World Health Organization. Global Disability Action Plan 2014-2021-Better Health for All People with Disability. (2015). Available from: http://apps.who. int/iris/bitstream/10665/199544/1/9789241509619_eng.pdf?ua=1 (accessed August 14, 2017)

32. Gupta N, Castillo-Laborde C, Landry MD. Health-related rehabilitation services: assessing the global supply of and need for human resources. BMC Health Serv Res (2011) 11:276. doi:10.1186/1472-6963-11-276

33. World Health Organisation. Noncommunicable Diseases (NCD) Country Profiles-Bangladesh. (2014). Available from: http://apps.who.int/iris/bitstr eam/10665/128038/1/9789241507509_eng.pdf?ua=1 (accessed August 20, 2017).

34. World Health Organization. Non-Communicable Disease Risk Factor Survey Bangladesh. (2010). Available from: http://www.who.int/chp/steps/2010_ STEPS_Report_Bangladesh.pdf (accessed August 20, 2017).

35. World Health Organization. Scaling Up Action Against Noncommunicable Diseases: How Much Will It Cost? (2012). Available from: http://www.who.int/ $\mathrm{nmh} /$ publications/cost_of_inaction.pdf (accessed July 26, 2017).

36. Haq S, Shazzad N, Ahmed S, Al-Qadir AZ, Shahin S. AB1157 prevalence of musculoskeletal disorders among garment industry workers in Bangladesh. Ann Rheum Dis (2017) 76:1460. doi:10.1136/annrheumdis-2017-eular.1966

37. Global Burden of Disease 2015 Disease and Injury Incidence and Prevalence Collaborators. Global, regional, and national incidence, prevalence, and years living with disability for 310 diseases and injuries, 1990-2015: a systematic analysis for the Global Burden of Disease study 2015. Lancet (2016) 388:1545-602. doi:10.1016/S0140-6736(16)31678-6

38. Norrefalk JR, Linder J, Ekholm J, Borg K. A 6-year follow-up study of 122 patients attending a multiprofessional rehabilitation programme for persistent musculoskeletal-related pain. Int J Rehabil Res (2007) 30(1):9-18. doi:10.1097/ MRR.0b013e328013dac8 
39. Korthals-de Bos IBC, Hoving JL, van Tulder MW, Rutten-van Mölken M, Ader A, de Vet H, et al. Cost effectiveness of physiotherapy, manual therapy, and general practitioner care for neck pain: economic evaluation alongside a randomised controlled trial. BMJ (2003) 326(7395):911. doi:10.1136/bmj. 326.7395 .911

40. Scottish Intercollegiate Guideline Network. Management of Chronic Pain (SIGN 136). (2013). Available from: http://www.sign.ac.uk/assets/sign136.pdf (accessed October 03, 2017)

41. World Health Organisation. The Global Status Report on Road Safety. (2015). Availablefrom:http://www.who.int/violence_injury_prevention/road_safety_ status/2015/en/ (accessed July 26, 2017).

42. Rahman A, Chowdhury SM, Mashreky SR, Linnan M, Rahman AKMF. Bangladesh Health and Injury Survey 2016: Summary Report. NonCommunicable Disease Control Progarmme, Directorate General of Health Services (DGHS), Ministry of Health and Family Welfare (MOHFW), Government of the People's Republic of Bangladesh (www.dghs.gov.bd), Centre for Injury Prevention and Research, Bangladesh (CIPRB; www.ciprb. org) (2016).

43. Islam MR, Rahman MS, Islam Z, Nurs CZB, Sultana P, Rahman MM. Inequalities in financial risk protection in Bangladesh: an assessment of universal health coverage. Int J Equity Health (2017) 16:59. doi:10.1186/ s12939-017-0556-4
44. Bultmann U, Sherson D, Olsen J, Lynsbeck-Hansen C, Lund T, Kilsgaard J. Coordinated and tailored work rehabilitation: a randomised controlled trial with economic evaluation undertaken with workers on sick leave due to musculoskeletal disorders. J Occup Rehabil (2009) 19:81-93. doi:10.1007/s10926-009-9162-7

45. Turner-Stokes L, Williams H, Bill A, Bassett P, Sephton K. Cost-efficiency of specialist inpatient rehabilitation for working-age adults with complex neurological disabilities: a multicentre cohort analysis of a national clinical set. BMJ Open (2016) 6(2):e010238. doi:10.1136/bmjopen-2015-010238

46. World Health Organization. Rehabilitation 2030: A Call for Action. (2017). Available from: http://www.who.int/disabilities/care/rehab-2030/en/ (accessed August 15, 2017)

Conflict of Interest Statement: The authors declare that the research was conducted in the absence of any commercial or financial relationships that could be construed as a potential conflict of interest.

Copyright $(0) 2018$ Mamin and Hayes. This is an open-access article distributed under the terms of the Creative Commons Attribution License (CC BY). The use, distribution or reproduction in other forums is permitted, provided the original author(s) and the copyright owner are credited and that the original publication in this journal is cited, in accordance with accepted academic practice. No use, distribution or reproduction is permitted which does not comply with these terms. 